\title{
COMPETITIVIDAD DE LA TARA PERUANA EN EL COMERCIO INTERNACIONAL, PERÍODO 2010-2018
}

\author{
Orlando Juan Márquez Caro* \\ https://orcid.org/0000-0003-4804-2528 \\ Ricardo Fernando Cosio Borda** \\ Fernando Luis Márquez Caro*** \\ https://orcid.org/0000-0001-9043-8150 \\ Manuel Alberto Luis Manrique Nugent**** \\ https://orcid.org/0000-0002-0816-2499
}

RECIBIDO: Septiembre 2019 / ACEPTADO: Diciembre 2019 / PUBLICADO: Mayo 2020

\begin{abstract}
Como citar: Márquez Caro, Orlando; Cosio Borda, Ricardo; Márquez Caro, Fernando; Manrique Nugent, Manuel. (2020). Competitividad de la tara peruana en el comercio internacional, período 20102018. Telos: revista de Estudios Interdisciplinarios en Ciencias Sociales, 22 (2), Venezuela. (Pp.258-280).

DOI: www.doi.org/10.36390/telos222.02
\end{abstract}

\section{RESUMEN}

El objetivo de la investigación fue determinar la competitividad de la tara peruana en el comercio internacional en el período 2010-2018, considerando las teorías de: World Economic Forum WEF (2018), Cann 2016), Gómez (2017), Cordero (2005), Porter 2008), Daniels, Radebaugh, y Sullivan (2013), Lerma y Márquez (2010), con un proceso metodológico que definió un estudio exploratorio por los datos fragmentados existentes que se recolectaron y seleccionaron de instituciones gubernamentales: Ministerio de Agricultura y Riego-MINAGRI (2009, 2010, 2017 a, 2017 b), Ministerio de Agricultura y Riego-MINAGRI y Servicio Nacional Forestal y de Fauna Silvestre-SERFOR (2016, 2017, 2018, 2019), Sistema Integrado de Información de Comercio Exterior- SIICEX (2019), Superintendencia Nacional de Aduanas y de Administración TributariaSUNAT (2019) y particulares: Sociedad Nacional de Industrias-SIN (2018), así como, por los escasos estudios acerca de la unidad de análisis, complementado con métodos de análisis de contenido y frecuencia. Los resultados concluyen que la tara peruana no es competitiva debido que mientras su producción fue descendente desde el año 2010 (32736 TM) hasta el 2018

\footnotetext{
* Dr. en Ciencias de la Educación, Profesor en la Universidad César Vallejo Lima Norte-Perú, Universidad Nacional del Callao-Perú, Universidad Nacional Autónoma de Huanta-Ayacucho-Perú. Líneas de investigación: Negocios internacionales: Competitividadoportunidad de negocios, Metodología de la investigación, Biofertilizantes-Medio ambiente-Nutrición, Educación. Correo electrónico: omrquezcaro@gmail.com

MBA en Administración, Profesor y Director de la Escuela de Negocios Internacionales en la Universidad César Vallejo Lima Norte-Perú. Líneas de investigación: Comercio Exterior, Turismo. Correo electrónico: ricardo.cosio.borda@gmail.com

3 Mg. en Investigación y Docencia Universitaria, Profesor de Investigación, Escuela de Negocios Internacionales de la Universidad César Vallejo, 2013 - 2019, Lima Norte, Perú. Líneas de Investigación: Metodología de la investigación, Responsabilidad Social. Correo electrónico: fema2207@gmail.com ORCID: https://orcid.org/0000-0001-9043-8150

**** Mg. en Administración de Negocios, Profesor Asociado en la Universidad Nacional Autónoma de Huanta-Ayacucho Escuela Profesional de Administración de Turismo Sostenible y Hotelería. Líneas de Investigación: Turismo, Ecología, Desarrollo Sostenible, Legislación Turística. Correo electrónico: manuelmanriquenu@gmail.com
} 
(25866 TM) su valor FOB tuvo un alza permanente desde el año 2010 (27075.9) a 39228.49 el año 2018, que el cálculo de Costo de los Recursos Domésticos (CRD) analizo por el factor precio indicando que sólo el año 2016 manifestó competitividad porque el precio internacional por $\mathrm{Kg}$. fue de cerca de $\$ 3.00$ dólares americanos en relación al precio doméstico de S/. 1.51 nuevos soles, además, por no cumplir satisfactoriamente los 12 pilares del enfoque de competitividad del World Economic Forum-WEF (2018); que permiten reflexionar acerca del tránsito de la estructura de exportación basada en ventajas comparativas a su transformación sustentada en ventajas competitivas que el país andino tramita.

Palabras clave: competitividad, exportación, cadena de valor, tara.

\title{
Competitiveness of Peruvian tare in international trade, 2010-2018 period
}

\begin{abstract}
The objective of the research was to determine the competitiveness of Peruvian tare in international trade in the period 2010-2018, considering the theories of: World Economic Forum - WEF (2018), Cann (2016), Gómez (2017), Cordero (2005), Porter (2008), Daniels, Radebaugh, and Sullivan (2013), Lerma and Márquez (2010), with a methodological process that defined an exploratory study for the existing fragmented data that were collected and selected from government institutions: Ministry of Agriculture and Irrigation-MINAGRI (2009, 2010, 2017 a, $2017 \mathrm{~b}$ ), Ministry of Agriculture and Irrigation-MINAGRI and National Forest and Wildlife ServiceSERFOR (2016, 2017, 2018, 2019), Integrated Foreign Trade Information System- SIICEX (2019 ), National Superintendence of Customs and Tax Administration-SUNAT (2019) and individuals: National Society of Industries-SIN (2018), as well as, for the few studies about the unit of analysis, complemented with content and frequency analysis methods. The results conclude that Peruvian tare is not competitive because while its production was down from 2010 (32736 MT) to 2018 (25866 MT) its FOB value had a permanent rise from 2010 (27075.9) to 39228. 49 In 2018, the calculation of the Cost of Domestic Resources (CRD) was analyzed by the price factor indicating that only 2016 showed competitiveness because the international price per $\mathrm{Kg}$. Was about US \$ 3.00 in relation to the domestic price of $S / .1 .51$ new soles, in addition, for not complying satisfactorily with the 12 pillars of the competitiveness approach of the World Economic ForumWEF (2018); that allow us to reflect on the transit of the export structure based on comparative advantages to its transformation based on competitive advantages that the Andean country processes.
\end{abstract}

Keywords: competitiveness, export, value chain, tare.

\section{Introducción}

Perú, está demostrando un gran potencial de desarrollo de productos agrícolas por la diversidad de factores que le generan ventajas comparativas Ricardo (2003), por ejemplo: Rosales (2019), refiere que la Palta Hass peruana es un producto que se exporta a más de 50 países a los que se agregarían éste año Corea del Sur y en los próximos años: México, Colombia, Australia y Nueva Zelanda; producto, que en términos de orden de exportación, es continuado por el Café peruano ubicado en el segundo lugar, luego por las Uvas peruanas que 
están en el tercer lugar y los Arándanos peruanos que se encuentran en el cuarto lugar con un valor FOB de U\$ 467 millones por concepto de valor de exportación Koo (2018).

En el pequeño ranking expuesto no se halla el producto agrario tara en ninguna de sus dos presentaciones, polvo o goma, pese que su exportación es catalogada beneficiosa, según comento Ministerio de Agricultura y Riego-MINAGRI (2009), "La tara es considerada el producto más rentable dentro del agro exportador peruano, debido a su gran acogida y altos precios mundiales [pese a las fluctuaciones existentes en temporadas]"(p.1) que amplía León (2018ª), al precisar que Perú sólo exporta 40 mil TM anuales de 100 mil toneladas que demanda el mundo, siendo el primer productor con el $90 \%$ del total. Más aún, es el segundo exportador (Sistema Integrado de Información de Comercio Exterior-SIICEX a, 2019), pese a la posibilidad de factores favorables que tiene.

El trabajo responde la siguiente pregunta: ¿Cuál es la competitividad de la tara peruana en el comercio internacional en el período 2010-2018? que se resuelve presentando, primero, una teorización de la competitividad relacionándolo con la cadena de valor de la producción de la tara y los 12 pilares del World Economic Forum-WEF (2018), luego, describiendo las características y propiedades del producto con su respectiva utilización reflejada en una matriz FODA, para, después, expresar su exportación al mercado internacional. Terminando con la descripción de la metodología aplicada, de los resultados y de las conclusiones.

\section{Competitividad en el comercio internacional de la tara peruana}

Reflexionar acerca de la competitividad es tratar un tema complejo, importante y sobre el cual no existe una conceptualización univoca, por ejemplo, Cann (2016), manifiesta: "En realidad existe una gran cantidad de definiciones. El Foro Económico Mundial que... [la mide]...entre países desde 1979 la define como el conjunto de instituciones, políticas y factores que determinan el nivel de productividad de un país"(p.1) . Relacionando competitividad con el nivel de productividad y tres grandes dimensiones: instituciones, políticas y factores que se tienen que tener en cuenta para interpretarla.

El último Informe de Competitividad Global 2018 del World Economic Forum - WEF (2018), sintetizado por nota de prensa de la Sociedad Nacional de Industrias-SNI (2018), permitió un enfoque innovador de la competitividad, debido que buscó responder a los desafíos del cambio tecnológico y a la 4ta. Revolución Industrial mediante, mediante 12 pilares de la competitividad ahora agrupados en 4 categorías: 1ra. Entorno habilitante, 2da. Capital humano, 3ra. Mercados y 4ta. Ecosistemas e Innovación (anteriormente fueron tres sub índices). Donde la valoración de Competitividad Global 4.0 mide la competitividad de 140 economías ( $90 \%$ del PBI mundial) a través de 98 indicadores organizados en los 12 pilares.

Tales pilares son: 1. Instituciones, 2. Infraestructura, 3. Adopción de TIC, 4. Estabilidad macroeconómica, 5. Salud (Esperanza de vida), 6. Educación y habilidades, 7. Mercado de productos, 8. Mercado de trabajo, 9. Sistema financiero, 10. Tamaño de mercado, 11. Dinamismo de negocios y 12. Capacidad de innovación. Midiendo con indicadores, con una escala de 0 a 100, el grado de avance de una economía hacia el estado ideal o "frontera" de competitividad.

Según el Informe, en los próximos años, crecerán en importancia el capital humano, la agilidad, la resiliencia y la innovación como elementos claves para incrementar la productividad 
y elevar la competitividad, que, a su vez, es fundamental para mejorar los niveles de vida y generar los recursos necesarios para alcanzar objetivos sociales. Resaltando, también, la existencia de un nexo causal entre la productividad y el crecimiento a largo plazo.

Señalo el informe del World Economic Forum - WEF (2018), que Perú ocupa la posición 63 entre 140 economías, el 4to. lugar en Sud América y 6to. en Latinoamérica y el Caribe, sintetizando su fortaleza en un rasgo muy importante: la estabilidad macroeconómica que los organismos oficiales presentan como la base de un crecimiento económico; enunciando, también, las principales debilidades aplicando indicadores de los pilares: Instituciones, infraestructura, educación, mercado de trabajo y capacidad de innovación, donde la primera muestra una gran debilidad, la segunda obsolescencia y escases, la tercera bajos logros de aprendizaje, la cuarta empleos de baja calidad en medio de subempleo y desempleo significativo por los grupos etarios jóvenes y, con poco desarrollo de innovación por las debilidades en la investigación, creación científica y tecnológica.

Fortalezas y debilidades que fueron relacionados y contrastados en la matriz FODA expuesta que considero indicadores de las actividades de la Cadena de Valor de Regiones Productoras y Procesadoras de tara de Perú, que sustentaron las conclusiones a las que se arribó.

Otro referente para medir la competitividad en el país Inca es la Política Nacional de Competitividad y Productividad decretada por el Consejo Nacional de Competitividad y Formalización (2019), que el Gobierno Peruano publicó al proponer objetivos relacionados a los 12 pilares comentados. Que tiene relación con la interpretación de Gómez (2017), quien entiende que la competitividad y la productividad tienen relación con la innovación como factor imprescindible, veamos:

“...En el caso de Latinoamérica, los rezagos de innovación parecen ser uno de los factores que más están afectando la productividad y el surgimiento de nuevos sectores, motores de crecimiento y de exportaciones. La diversificación de las economías de la región, jalonada por mejoras en productividad, requiere entonces avanzar en los temas de innovación... El pilar de innovación incluye indicadores de la capacidad empresarial para innovar, la calidad de las instituciones de investigación científica, el gasto en I\&D, la colaboración academia-industria, la contribución de las compras públicas, la disponibilidad de científicos e ingenieros, la aplicación a patentes y la protección de la propiedad intelectual. Cada uno de estos indicadores ha sido identificado en la literatura académica y en casos de estudio como factores que explican resultados de innovación a nivel de país." (p. 6)

Con las limitaciones del caso, Latinoamérica si "...ha avanzado en la gestación de ecosistemas de innovación, donde se facilitan los espacios... entre actores diversos del sistema-incluyendo academia, empresas, emprendedores, inversionistas que resulta en flujo de ideas conducente a innovación" Gómez (2017: 8). Sin embargo, en Perú están presentes limitaciones para el desarrollo de la innovación, como, por ejemplo, la insuficiente inversión en I\&D, en infraestructura, etc. que explican los escasos avances en la competitividad y exportación de la tara.

Definiendo a los sujetos de competencia explicó Cordero (2005: 23) que "... ¿son las naciones o las empresas? Dada la importancia creciente de las segundas y el nuevo papel que 
ha asumido el Estado,...son las empresas las que compiten [y]...el Estado el que ofrece el entorno necesario..."(p. 23). Entonces, los sujetos de la competencia en el Perú, son las empresas productoras y/o exportadoras de tara siendo el Estado quien actúa a través de políticas, normas, infraestructura, etc., marcando, principalmente, las organizaciones, el nivel de competitividad existente.

La competitividad es un concepto que no tiene límites precisos y se define en relación con otros conceptos como lo enfoco Porter (2008), quien amplio su fundamento formulando la ventaja competitiva comprendiendo los mercados segmentados, los productos diferenciados, las diferencias en las tecnologías y las economías de escala, donde la competencia es dinámica y evolutiva por qué las empresas de una nación consiguen ventaja competitiva en todas sus formas, que menciona Paz (2017), como factores de la competitividad que significa obtener un alto rendimiento con la mejora continua en los procesos y con estándares de calidad, así como, con las orientaciones del World Economic Forum - WEF (2018): instituciones, políticas, factores, doce pilares que se agrupan en cuatro categorías.

En concordancia con lo comentado, se analizó la competitividad de la tara peruana en el comercio internacional aplicando "...el enfoque de cadena de valor como método de análisis ....para] entender las relaciones funcionales - producción, acopio, transformación y comercialización - ...que se establecen entre los actores desde la producción primaria hasta el consumo final" que refirió Chávez (2013: 3 y 7), que ha sido el sustento de análisis de la cadena de valor de la tara en regiones diversas: Cajamarca Chávez (2013), La Libertad (Universidad Nacional Agraria La Molina-UNALM, 2015), Amazonas (Ministerio de Comercio Exterior y Turismo-MINCETUR, 2007) y Ayacucho Avendaño (2008), que se presenta en el FODA de la cadena de valor de regiones productoras y procesadoras del producto, considerando, también, indicadores de Competitividad Global 2018 del World Economic Forum - WEF (2018).

El concepto de cadena de valor se refiere a la coordinación entre los actores directos (los involucrados en los procesos de provisión de insumos, producción primaria, acopio, transformación, comercialización y consumo final) e indirectos (entidades e instituciones de apoyo, públicas y privadas, que cumplen diferentes funciones de soporte al desarrollo de la cadena en los distintos niveles micro, meso y macro) que cumplen funciones a lo largo de la cadena. Su análisis permite interpretar la puesta en valor de cada actividad para concluir en la productividad que generan que tiene relación con la productividad. Veamos la siguiente tabla:

\section{Tabla 1}

Actores de la cadena de valor de tara

\begin{tabular}{|l|l|}
\hline Actores Directos & Actores Indirectos \\
\hline Proveedores de insumos & Proveedores de asistencia técnica \\
\hline Productores Primarios (recolectores y emprendedores) & Transportistas \\
\hline Productores empresas & Estado con sus organismos \\
\hline Acopiadores: Pequeños, medianos, mayoristas & Entidades de Apoyo \\
\cline { 1 - 1 } $\begin{array}{l}\text { Empresas transformadoras: Grandes, medianas, } \\
\text { pequeñas }\end{array}$ & \\
\cline { 1 - 1 } Empresas exportadoras: Grandes, medianas, pequeñas & \\
\cline { 1 - 1 } $\begin{array}{l}\text { Consumidores finales: } 3 \% \text { mercado interno, mayormente } \\
\text { mercado externo como insumo para industrias diversas }\end{array}$ & \\
\hline
\end{tabular}

Fuente: Chávez (2013: 32). Adaptación propia 
Las fases de la producción de la tara, son: Provisión de insumos (Por el bajo nivel tecnológico usado en la producción de tara, este es un eslabón muy débil, limitándose a unos pocos insumos que abastecen campesinos con abonos orgánicos $y$, otros son los comerciantes que suministran materiales y herramientas); producción (Segundo eslabón con actividades vinculadas con el manejo del cultivo: producción de plantones, plantación, remoción del terreno, deshierbo, abonamiento, riego, poda, raleo, cosecha de la vaina y postcosecha); acopio (Tercer eslabón que abarca actividades de estiba y desestiba, selección, almacenamiento, taqueado, empaque y transporte del producto).

Asimismo, transformación (Eslabón que permite darle valor agregado al producto mediante varios procesos (donde prima lo artesanal) que la mayoría de las veces se realiza fuera de las regiones productoras en plantas industriales indicadas; comercio (Quinto eslabón de la cadena por el cual se exporta el producto transformado, como insumo, para la fabricación de diversos productos en otros países. En él es necesaria la logística portuaria y aduanera; consumo (donde están las empresas extranjeras que la procesan como insumo industrial para llegar al consumidor final, seis fases indicadas por Chávez, Manuel (2013). La siguiente figura ayuda a mostrar lo comentado de las fases de la cadena de valor.

\section{Figura 1}

\section{Mapeo de la cadena productiva de la tara}

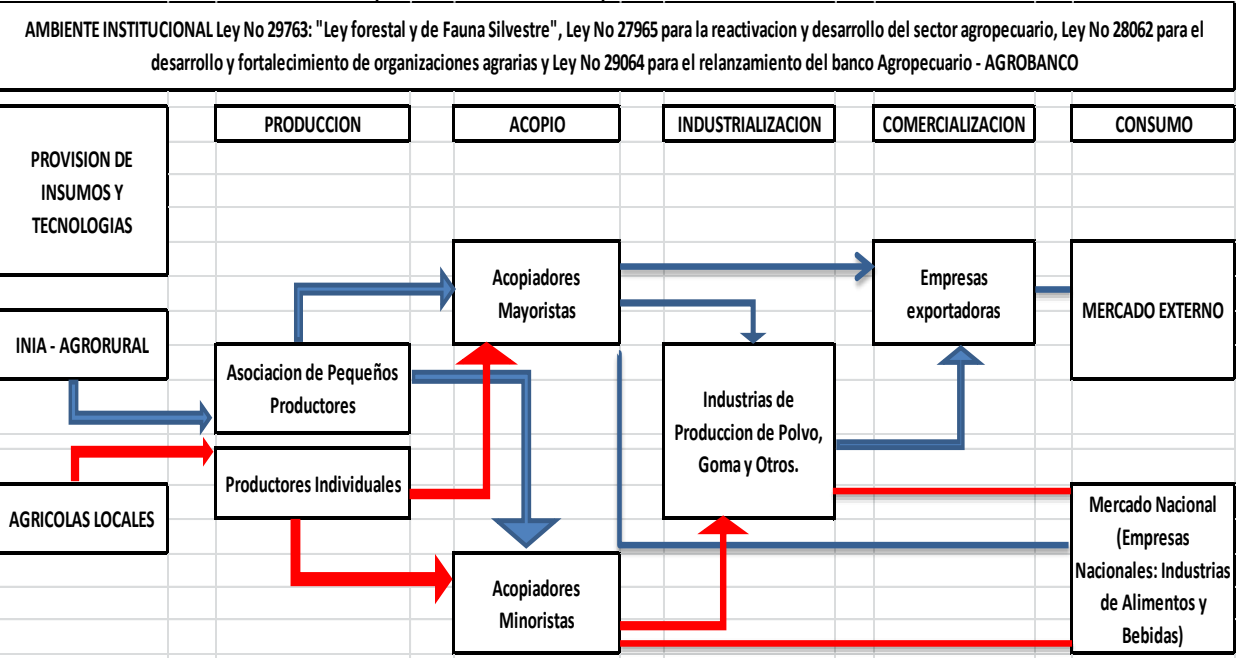

SECTORES CONEXOS Y APOYO: Gobiernos Regionales, Gobiernos Locales, SENASA, Universidades, Produce, Sierra Exportadora, Aduanas, Sunat, etc.

Fuente: Llacchuas (2016: 36). Adaptación propia

\section{El producto agrario tara}

Ministerio de Agricultura y Riego-MINAGRI (2017a: 3) describe a la tara Caesalpinia spinosa (Molina) Kuntze como un arbusto originario de los Andes de Perú, considerándola especie forestal nativa y familia de las leguminosas que crece en climas semitropicales y subtropicales 
entre los 800 y 2,800 msnm., en la costa y en los valles interandinos entre los 1.600 y los 2.800 msnm. Entendida como un recurso no maderable del bosque Chávez (2013: 7), componente de la biodiversidad nativa peruana que es un factor favorable para el país andino, que la uso desde la época prehispánica hasta la actualidad en la medicina tradicional por sus propiedades curativas y como fuente de leña, así como en la actividad textil para el teñido de lanas y en la artesanía y la industria del cuero para la curtiembre.

Durante años, la tara, creció en bosques naturales como una especie silvestre desarrollándose en las últimas décadas, también, en bosques cultivados ampliándose su habitad natural, aumentando de su origen en la sierra a la siembra en la costa, lográndose así, en los últimos diez años, la estacionalidad del producto a todos los meses porque de cosecharse entre mayo a noviembre en la sierra los meses restantes se realizan en la costa, política y acción que respondió a su creciente demanda en el mercado internacional por convertirse en un insumo para la elaboración de diversos productos y así generar rentabilidad como menciono Ministerio de Agricultura y Riego- MINAGRI (2017a).

El núcleo de la tara, su fruto, crece en diversas regiones de la costa (Ica, La Libertad, Lambayeque, Lima y Arequipa) y de la sierra (Ancash, Cajamarca, Huánuco, Huancavelica, Apurímac y Ayacucho) representando importantes hectáreas, 17,000 León (2018 b). Sus frutos son vainas aplanadas de color amarillo naranja de hasta diez centímetros de largo y dos de ancho, que contienen hasta siete semillas redondeadas de 0,6 a 0,7 centímetros de diámetro de color pardo negruzco cuando están maduras. Su siembra se realiza vía semilla botánica y su germinación se inicia entre los ocho y los doce días y finaliza a los veinte. Produciéndose en tres sistemas: Bosques naturales, agro forestal y plantas cultivadas en macizo, cada cual con sus características de producción y productividad que analizamos.

La producción de tara ha tenido una evolución ascendente, pero, a la vez, con fluctuaciones Ministerio de Agricultura y Riego-MINAGRI (2017a: 3) en el período 2000-2018, que se muestra en la tabla y figura contigua. Desde el año 2000 al 2014 subió de 2750 a 35566 toneladas producidas teniendo un punto alto, en el 2012, en 38328 TM., con una tasa de crecimiento anual de $20,1 \%$, que descendió el 2015 a 27665 toneladas con $22 \%$, "...que entre otros factores [habría sido por] la caída de la producción de las otrora importantes zonas productoras: Cajamarca y La Libertad, afectadas por problemas climáticos".

Según el Ministerio de Agricultura y Riego-MINAGRI y Servicio Nacional Forestal y de Fauna Silvestre-SERFOR $(2016,2017,2018)$, y el Ministerio de Agricultura y Riego-MINAGRI y Servicio Nacional Forestal y de Fauna Silvestre-SERFOR (2019: 133), la producción del producto en el año 2016 fue de 12617 TM, en el 2017: 23978 TM., y en el 2018: 25866 TM. De acuerdo a los datos expuestos, recorriendo todo el período 2010-2018, que investigamos, empieza un alza significativa al final del primer decenio del siglo XXI para luego tener caídas significativas en su producción como las del 2015 (27665 TM.) y del 2016 (12617 TM.) con el inicio de una recuperación el 2017 (23978 TM.) y el 2018 (25866 TM.) con una variación porcentual favorable de 10, 4, siendo así un rasgo importante las variaciones en las cantidades de producción que debilitaron la oferta exportable.

Siendo las principales regiones productoras (Ministerio de Agricultura y Riego-MINAGRI, 2017 a) en orden de importancia: Cajamarca (45\%), La Libertad (18\%), Ayacucho (14\%), Huánuco, Apurímac, Ancash, Amazonas y Cusco con los porcentajes restantes. 
Tabla 2

Producción de tara peruana período2010-2018 (Toneladas métricas)

\begin{tabular}{|c|r|}
\hline Años & $\begin{array}{c}\text { Producción } \\
\text { en Toneladas }\end{array}$ \\
\hline 2010 & 32,736 \\
\hline 2011 & 30,000 \\
\hline 2012 & 38,328 \\
\hline 2013 & 32,000 \\
\hline 2014 & 35,566 \\
\hline 2015 & 27,666 \\
\hline 2016 & 12,617 \\
\hline 2017 & 23,978 \\
\hline 2018 & 25,866 \\
\hline
\end{tabular}

Fuente: Ministerio de Agricultura y Riego-MINAGRI (2017a, p 3), Ministerio de Agricultura y Riego-MINAGRI y Servicio Nacional Forestal y de Fauna Silvestre-SERFOR (2016) y Boletín Estadístico Mensual-diciembre 2018 (MINAGRI, 2019, p 133). Adaptación propia

El ordenamiento y organización de la producción de la tara para efectos de su comercialización y exportación ha tenido un proceso importante, que aún no concluye. A partir de la década de 1970 Chávez (2013) empezó a ganar espacio como fuente de materia prima para la elaboración de diversos productos y desde el año 2003, por la importancia que adquirió, se realizaron diagnósticos regionales de la cadena productiva de la tara en regiones como Cajamarca y Ayacucho-2005. El año 2006 se realizó en la ciudad de Lima el I Encuentro Nacional "Realidad y Propuesta para el Desarrollo Competitivo de la Tara en el Perú"; el 2007 (abril) en la ciudad de Cajamarca fue el II Foro Nacional para el Desarrollo de la Tara, donde se constituyó la Comisión Transitoria para la conformación del Consejo Nacional, que más tarde sería CONATARA.

Continuando el proceso, el año 2008 se produjo el III Foro Nacional de la Tara "Competitividad e Inclusión Económica" en la ciudad de Ayacucho y, el año 2009 se desarrolló el IV Foro Nacional de la Tara en la ciudad de Huaraz. Obteniéndose un marco legal como primer corolario con la constitución del Consejo Nacional de la Tara-CONATARA, mediante Resolución Suprema No 013-2010-AG (Ministerio de Agricultura y Riego-MINAGRI, 2010) con el propósito de lograr "...un espacio de concertación e institucionalización del diálogo y cooperación entre los agentes, públicos y privados, inmersos en los ciclos del proceso productivo de la cadena agrícola... [y así] generar compromisos ... de competitividad; para darle mayor valor agregado a la tara". Apareciéndose como preocupación central la competitividad del producto.

Actualmente, la producción de tara es normada por la Ley No 29763 Ley Forestal y de Fauna Silvestre (García y Fernández, 2011), con las modificaciones específicas de algunos artículos emitidas en diciembre del 2016 (seis años después) para facilitar el otorgamiento de derechos para el aprovechamiento sostenible de los recursos forestales y de fauna silvestre, que tiene mayor significancia en el artículo $2^{\circ}$, "...que señala que el aprovechamiento exclusivo de frutos y semillas silvestres, mediante su recolección, que no implique la tala de la planta del que proviene, no requiere de un plan de manejo forestal, tal como estaba establecido." (Ministerio de Agricultura y Riego-MINAGRI, 2017a: 3), corrigiendo así limitaciones.

Sin embargo, pese a las modificaciones normativas, no convence totalmente por críticas existentes (Telge, 2018) que indicó que la producción de tara "...necesita un marco legal ad- 
hoc... [Porque] recibe el mismo tratamiento de un producto forestal y tiene muy poco apoyo". Entendiéndose, entonces, que en el período del 2011 (julio) al 2016 (diciembre) la normatividad que orientaba la comercialización de las semillas de tara no fue la más pertinente, lo que podría explicar los altibajos que sucedieron en su producción.

En concordancia con lo expuesto la tabla No 3, por el análisis de la información de la cadena de valor de la tara que consideró como ámbito de actuación las tres principales regiones productoras en Perú: Cajamarca (45\%), La Libertad (18\%), Ayacucho (18\%) como la de baja producción: Amazonas (1\%); incluyendo a las ciudades de Lima, Chiclayo, Trujillo y Huanta que cuentan con empresas procesadoras que realizan la fase de transformación, considerando los 12 pilares que propone el World Economic Forum - WEF (2018), se logró la siguiente interpretación:

\section{Tabla 3}

Debilidades en las actividades de la cadena de valor según Pilares del World Economic Forum - WEF (2018)

\begin{tabular}{|l|l|}
\hline No y Pilar & Indicador \\
\hline 1: Instituciones & $\begin{array}{l}\text { Organizaciones débiles y muy primarias de productores, por lo que } \\
\text { debería aplicarse el Modelo de los Valores en Competencia (MVC) } \\
\text { formulado por Cameron y Quinn como indican Ojeda, Méndez y } \\
\text { Hernández (2016) para determinar el criterio de efectividad } \\
\text { organizacional; en el sistema financiero. }\end{array}$ \\
\hline 2: Infraestructura & $\begin{array}{l}\text { El mal estado de las vías de comunicación que se usan para el } \\
\text { traslado. }\end{array}$ \\
\hline 3: Adopción de Tics. & No hay presencia significativa. \\
\hline 4: Estabilidad macroeconómica & El gobierno indica que es una de sus fortalezas. \\
\hline 5: Salud (Esperanza de vida) & Hay datos que muestran serias debilidades. \\
\hline 6: Educación y habilidades & $\begin{array}{l}\text { Visión empresarial reducida y poco conocimiento de la demanda } \\
\text { del producto en los mercados extranjeros; en la capacidad de } \\
\text { innovación. }\end{array}$ \\
\hline 7: Mercado de productos & $\begin{array}{l}\text { Se producen cambios climáticos en las zonas productoras (helada, } \\
\text { granizada, sequía) y presencia e incremento de plagas con riesgo } \\
\text { frecuente en la producción, como también, bajo rendimiento en la } \\
\text { producción por la existencia de plantaciones de tara de cierta } \\
\text { antigüedad y preponderancia de bosques naturales, asimismo, } \\
\text { otro riesgo que toman los productores como peligro latente, es el } \\
\text { incremento de operaciones mineras en zonas productoras y } \\
\text { adyacentes a las áreas de crecimiento de la tara. }\end{array}$ \\
\hline 8: Mercado de trabajo & $\begin{array}{l}\text { Hay escasa presencia de profesionales especializados en la } \\
\text { actividad de producción y de exportación. }\end{array}$ \\
\hline 9: Sistema financiero & $\begin{array}{l}\text { Escasos recursos y apoyo a productores. } \\
\text { del mismo. }\end{array}$ \\
\hline 10: Tamaño de mercado & $\begin{array}{l}\text { El mercado externo muestra fluctuaciones en los precios con } \\
\text { tendencia a la disminución en coyunturas, así como, existe }\end{array}$ \\
\hline 11: Dinamismo de negocios & \\
\hline
\end{tabular}




\begin{tabular}{|l|l|}
\hline & $\begin{array}{l}\text { presencia de competencia en la venta del producto por otros } \\
\text { países ofertantes al mercado internacional. }\end{array}$ \\
\hline 12: Capacidad de innovación & $\begin{array}{l}\text { Limitada información tecnológica acerca de los procesos de } \\
\text { transformación del producto que no permiten un mayor valor } \\
\text { agregado, que va de la mano con la poca capacitación y } \\
\text { desinformación de los actores que participan en la cadena de } \\
\text { valor, por ejemplo, se incurre en prácticas inadecuadas en la } \\
\text { cosecha, poca eficiencia en la clasificación del producto y, en la } \\
\text { postcosecha, un almacenaje que no es óptimo por los ambientes } \\
\text { que se usan; entre otras. }\end{array}$ \\
\hline
\end{tabular}

Fuentes: Chávez (2013, pp. 19, 20, 21), Avendaño (2008, pp. 24, 25 y 26), Universidad Nacional Agraria La Molina-UNALM (2015), Ministerio de Comercio Exterior y Turismo-MINCETUR (2007, p 5), Ministerio de Agricultura y Riego-MINAGRI y Servicio Nacional Forestal y de Fauna Silvestre- SERFOR (2017, p 24). Adaptación propia.

Leyenda: $P=P i l a r e s$, Número=Numeración de pilar de acuerdo a World Economic Forum-WEF (2018).

Por lo tanto, los impulsores de la productividad manifiestan serias limitantes para la competitividad de la tara y para su flujo de exportación, y más aún, no tienen presencia clara los pilares $3,4,5$ y 10. Información que se basó en la matriz FODA formulada en la tabla No 4, también, con los datos de las regiones productoras de Perú citadas, en la cual se expresa un panorama más amplio de la producción del producto.

\section{Tabla 4}

FODA de actividades de la Cadena de Valor de Regiones Productoras y Procesadoras de tara

\begin{tabular}{l}
\hline Fortalezas \\
\hline La región de Ayacucho es apropiada para la producción de tara con productos de calidad por su alto \\
contenido de taninos, de producción orgánica, soportando almacenamiento prolongado. En las partes \\
bajas se pueden obtener hasta dos campañas por año. \\
En la región Cajamarca gran parte de la población de tara está compuesta de bosques o árboles \\
nativos (66\%) y otro en sistemas agroforestales (34\%). \\
Perú, principal productor de tara en el mundo con el $90 \%$ del total. \\
Prolongada vida útil del árbol de la tara. \\
Cultivo orgánico y ecológico, con bajo uso de agroquímicos. \\
Favorables condiciones climáticas (Sur de la región Amazonas y lugares de otras regiones) y del \\
suelo para el cultivo y producción durante todo el año, variando el calendario de acuerdo a la \\
estacionalidad creada en ellas. \\
P11. Dinamismo de negocios \\
Costos de producción bajos pudiendo competir con otros productos sustitutos y ofertarlos \\
favorablemente en el mercado. \\
El rendimiento registrado en los últimos años varía de acuerdo con el lugar, el sistema de producción \\
y las características del productor. Se puede encontrar tres niveles de producción: Mala: menor de un \\
quintal por planta, regular: de uno a dos quintales por planta y buena: mayor de dos quintales por \\
planta.
\end{tabular}


Especie adaptada por los productores a diferentes condiciones ambientales subtropicales y templadas permitiendo una estacionalidad permanente.

La producción de plantones forestales se hace en viveros con todas las especificaciones técnicas que requiere el cultivo.

La postcosecha es una actividad que permite seleccionar el producto adecuadamente y la producción de plantones forestales.

La transformación incluye varios procesos y se realiza la mayoría de las veces fuera de las regiones productoras en plantas industriales.

Existencia de una transformadora y exportadora en Huanta región Ayacucho.

Las empresas transformadoras poseen grandes almacenes en Lima, estoqueándose en julio y agosto porque en estos meses la tara está madura y tiene mejor calidad. Un grupo de seis empresas concentra la adquisición de la tara de la región Cajamarca.

\section{Educación y habilidades}

En su crecimiento silvestre se explota de dos formas: Por campesinos recolectores de las vainas sin aplicar manejo técnico alguno y, por productores emprendedores que aplican técnicas básicas, manejo forestal mediante plantaciones, se organizan y se informan en instituciones.

Productores, acopiadores, transformadores y exportadores desarrollan progresivamente capacidades desarrolladas para la comercialización del producto.

\section{P1. Instituciones}

En algunas localidades de Cajamarca, Ayacucho, Amazonas, Apurímac, etc. se ha impulsado un proceso de desarrollo organizativo para la comercialización y producción.

En algunas regiones, como Ayacucho, hay red de acopiadores funcionando.

\section{P2. Infraestructura}

Presencia de vías acceso a centros de producción y a mercado en la región Ayacucho

En la región Amazonas existencia de la Carretera Marginal asfaltada, que permite transportar y comercializar el producto a la Costa.

\section{P9. Sistema financiero}

Las empresas exportadoras son empresarios individuales o empresas dedicadas a la venta de derivados de tara en los mercados del exterior. Tienen acceso al sistema financiero nacional e internacional para financiar sus costos de preembarque y algunas habilitan grandes sumas de dinero a los acopiadores provinciales para la adquisición de tara en vaina.

\section{Debilidades}

\section{Mercado de productos}

En la región Cajamarca se explota mayormente la tara que procede de los bosques naturales (98\%) y solo un pequeño volumen $(2 \%)$ de plantaciones forestales instaladas.

Los problemas fitosanitarios son provocados por plantas parásitas que debilitan y/ o matan a la tara, sucediendo que los productores no recurren a controles fitosanitarios debido a la escasez de conocimientos y asistencia técnica oportuna.

Amplio período vegetativo de la tara para que produzca (3 años aproximadamente).

Dispersión de plantaciones. Crecimiento limitado y desordenado de la oferta.

\section{P11. Dinamismo de negocios}

Falta de una oferta productiva y exportable organizada

En la región Cajamarca sólo un $61 \%$ de productores invierte en insumos como abonos, compra de plantones forestales, herramientas para el manejo del cultivo y sacos de polietileno para ensacar las vainas cosechadas, que son provistos mayormente por campesinos mediante abono orgánico y comerciantes que suministran materiales y herramientas. 


\section{Debilidades}

Alta dispersión y fragmentación de las tierras y de la oferta productiva (producción atomizada). La utilidad se genera solamente en plantaciones establecidas con una densidad de siembra alta y adecuada, es decir, casi 600 plantas por hectárea; no así en los bosques naturales, donde las plantas de tara no están tan concentradas.

Reducido nivel de transformación del producto en las plantas procesadoras.

En la región Ayacucho inexistencia del Plan Regional de la tara.

\section{P12. Capacidad de innovación.}

El cultivo de la tara se caracteriza por la deficiente tecnología de producción, cosecha y poscosecha porque está basada en el conocimiento tradicional, con muy limitado acceso a técnicas de silvicultura que permitirían elevar la productividad y la rentabilidad para la exportación.

En la región Cajamarca el sistema más usado para el riego de las plantas es el riego por gravedad o inundación $(71 \%)$, otra forma frecuente es el riego con recipientes como «baldes o botellas descartables» $(29 \%)$, manifestándose una deficiente infraestructura de riego y drenaje.

En la región Amazonas el acopio se realiza en centros rústicos y áreas bajo techo que cumplen la función de almacén, arrendadas a los propios productores, existiendo pocos lugares establecidos para ello.

Inadecuadas prácticas de cosecha (densidad, manejo de plagas y enfermedades) y post cosecha. Los productores recolectores (Actor directo) sólo hacen el recojo, ensacado, acarreo y transporte para la venta en forma tradicional, no se organizan ni tienen interés en tecnificarse.

\section{P2. Infraestructura}

El comercio requiere de la intervención de logística vial, portuaria y aduanera; existiendo deficiente infraestructura vial en diversos lugares de las regiones productoras y comercializadoras.

En la región Amazonas limitada cobertura de energía eléctrica en las zonas rurales

\section{P1. Instituciones}

Negociaciones poco transparentes en mercado entre los acopiadores locales y los acopiadores provinciales (engaño en el peso y en el cálculo del valor), existiendo demasiados canales de comercialización.

Cadena poco integrada y articulada entre actores.

Normatividad poco clara que limita su aplicabilidad

\section{P6. Educación y habilidades}

Desconocimiento de prácticas de gestión empresarial y de mercado por parte de los productores y acopiadores locales. Por ejemplo, en cuanto a la venta, en general, no existe por parte de los productores mayor control de calidad de la tara que entregan. En la región Cajamarca sólo 39\% de los productores selecciona el producto y $61 \%$ no lo hace. Existiendo limitadas prácticas asociativas entre ellos.

Escasa sensibilización, programas y actividades orientadas a la forestación del productor y de la sociedad en general.

Limitado conocimiento de costos de producción y comercialización, principalmente de productores y acopiadores locales al haber escasa disponibilidad de información de carácter técnica y comercial.

\section{P9. Sistema financiero}

Limitado acceso de actores locales a servicios empresariales como el financiamiento.

\section{Oportunidades}

\section{P7. Mercado de productos}

Creciente demanda en el mercado internacional de productos orgánicos y naturales. 
Demanda de los sub productos de la tara como insumo industrial por empresas foráneas para continuar su procesamiento y llegue al consumidor final.

La prohibición, en países de la Unión Europea, de insumos como plomo, mercurio, cadmio y cromo en la fabricación de cueros usados en autos.

Perú primer productor de tara a nivel mundial con $90 \%$ del total.

\section{P11. Dinamismo de negocios}

Incremento de la demanda en Estados Unidos, Italia, España (Principalmente polvo de tara-región La Libertad), Japón, y países de la Unión Europea, por la aplicación de tara en la industria farmacéutica, química, etc.

\section{P6. Educación y habilidades}

Amplia diversidad de usos y aplicaciones de la tara en: medicina tradicional (mercado interno y en cantidades menores y colorantes, $3 \%$ ); industrias de alimentos y bebidas, química y farmacéutica; curtiembres; cosmetología (En el extranjero), etc.

\section{P1. Instituciones}

Inversión en reforestación por parte de INRENA, Fondo Ítalo Peruano y otras instituciones nacionales y extranjeras.

Espacios de concertación y dialogo interinstitucionales-organismos públicos y privadas- para el desarrollo de la cadena productiva del producto (CONATARA, SNI, ADEX, fondos de cooperación internacional, etc.)

\section{P11. Dinamismo de negocios}

Interés de empresarios de Lima en invertir en las regiones productoras.

Convenios y tratados internacionales (TLC). Ferias internacionales.

\section{P4. Estabilidad macroeconómica}

La estabilidad macroeconómica que los organismos oficiales presentan como la base de un crecimiento económico (WEF).

Bajo índice de inflación que se mantiene dentro del rango meta.

\section{Amenazas}

\section{P11. Dinamismo de negocios}

Fluctuaciones de alzas y bajas de los precios del producto en el mercado internacional.

Competencia creciente de China y otros países.

\section{P7. Mercado de productos}

Restricción de la Unión Europea para el ingreso de productos naturales (Regulaciones sanitarias: Certificado Fitosanitario, Certificado de Calidad). Garantías y bonos que se usan en el comercio exterior.

Existencia de productos sustitutos y de competencia (productos vegetales y sintéticos).

Instalaciones intensivas de tara en otros países.

Condiciones climáticas adversas (sequías) con desordenes climáticos extraordinarios (Fenómeno del Niño)

Incremento de la deforestación y presencia de operaciones mineras en algunas zonas de producción y/o cercanas a las áreas de crecimiento de la tara.

\section{P1. Instituciones}

Inestabilidad política y económica

Políticas del Estado desfavorables para la explotación y exportación del producto.

Instituciones débiles (WEF). 


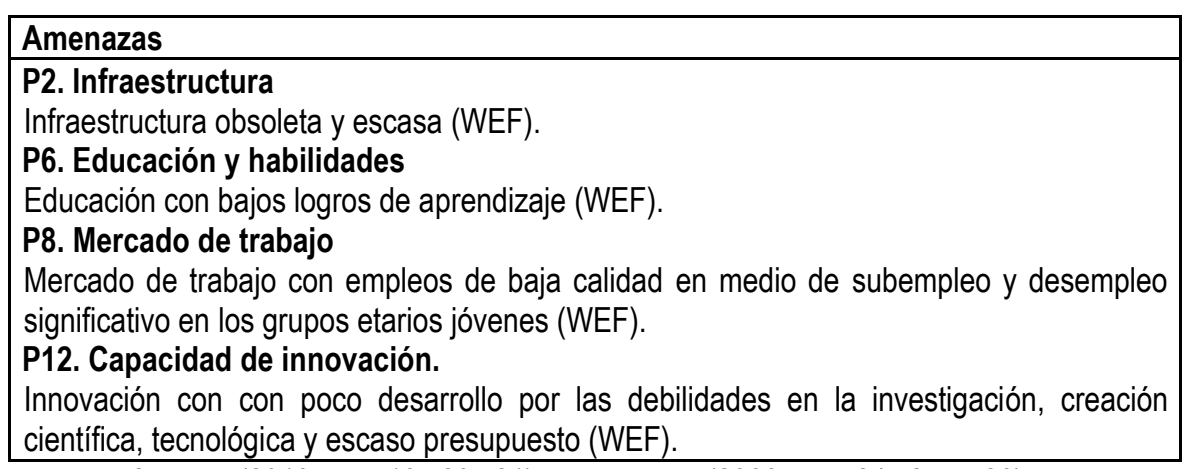

Fuentes: Chávez (2013, pp. 19, 20, 21), Avendaño, (2008, pp. 24, 25 y 26), Universidad Nacional Agraria La Molina-UNALM (2015), Ministerio de Comercio Exterior y TurismoMINCETUR (2007, p 5), Ministerio de Agricultura y Riego-MINAGRI y Servicio Nacional Forestal y de Fauna Silvestre- SERFOR (2017, p 24). Adaptación propia.

Leyenda: $P=P i l a r e s$, Número=Numeración de pilar de acuerdo a World Economic Forum-WEF (2018).

\section{Exportación de tara}

La exportación es un concepto que se aplica permanentemente en los negocios internacionales, Daniels, Radebaugh y Sullivan (2013: 483) la mencionan como "...la venta de bienes y servicios producidos por una empresa con sede en un país a clientes que residen en otro país" (p.483), siendo exportadores los primeros e importadores los segundos. Presentándose la posibilidad de una exportación directa o de una exportación indirecta. En el primer caso, la organización vende directamente sus productos a un intermediario independiente, como un agente, distribuidor o minorista ubicado fuera del país de origen del producto. En el segundo caso la empresa vende sus productos a un intermediario independiente ubicado en el mercado doméstico, que luego exporta el producto a sus agentes extranjeros que luego lo venden al consumidor final.

Lerma y Márquez (2010), refieren la siguiente opinión de exportación: “...es una actividad vital dentro de los negocios internacionales y consiste en comercializar los productos o servicios fuera de los límites territoriales del país al que pertenece el oferente, junto con las importaciones integra el concepto de comercio internacional" (p. 539). Complementando la anterior opinión es importante resaltar el criterio de que la exportación es vital en los negocios internacionales y que al lado de la importación conforman el concepto de comercio internacional. Y, respecto a la actividad de exportación de los países latinoamericanos, donde se ubica Perú, Gómez (2017) indico:

"El fin del boom de precios de bienes básicos, con la fuerte caída de precios de petróleo, minerales, y en menor medida bienes agrícolas, puso en evidencia la vulnerabilidad de muchas economías latinoamericanas a choques externos... Al caer los precios de sus principales productos de exportación, el valor de las exportaciones en la región cayó, aumentando déficits comerciales que a su vez aumentaron los déficits de cuenta corriente [coyuntura 2014-2016]." (p.2) 
Tal situación que, no sólo afectó a los países del Sur, motivo la aplicación de políticas económicas de búsqueda de apertura de nuevos y más mercados, en los que las empresas puedan fortalecerse, ya sea mediante el incremento de sus exportaciones, la incursión a nuevos destinos o bien la exportación de productos diferentes de los tradicionales, que Perú desarrolla desde años atrás enfrentando el reto de lidiar con otros productores que gozan de las mismas ventajas en la apertura de mercados, pero con diferentes niveles de competitividad, que en el país andino es débil.

La creación, incentivación y reforzamiento de las estructuras de exportación, para transitar de un modelo de inserción internacional mediante las ventajas comparativas a un modelo de promoción de las exportaciones con base en las ventajas competitivas, en el que transita el país Inca, se produce, en un contexto mundial de dinamismo en el comercio, junto con el desbordamiento de las fronteras productivas, la innovación tecnológica, la reducción de los costos de transporte y de las barreras arancelarias, así como la intensificación en la transacción de servicios financieros, que en América Latina se realiza lentamente y en forma dispar. Además, primando, mayormente ventajas estáticas, como mano de obra y recursos naturales, manifestándose más la ausencia de mano de obra calificada y el agotamiento de los recursos naturales.

Dicha estrategia se desarrolló mejor en algunas regiones, como el Asia del Pacífico, donde la producción se ha desplazado de la explotación o producción con base en los recursos naturales o humanos disponibles a una producción con base en el conocimiento y la innovación tecnológica, el uso de recursos humanos capacitados o de conocimiento, Cordero (2005: 7,8, 12). En dicho contexto se produce la exportación de tara peruano al mercado global con las siguientes partidas de exportación del producto y derivados, veamos:

\section{Tabla 5}

Partidas arancelarias del producto, exportadas en los últimos años

$\begin{array}{ll}2912193000 & \text { GLUTARALDEHIDO } \\ 1302399000 & \text { LOS DEMAS MUCILAGOS Y ESPESATIVOS DERIVADOS DE LOS VEGETALES } \\ 1301909090 & \text { LOS DEMAS } \\ 1302391000 & \text { MUCILAGOS DE SEMILLA DE TARA (CAESALPINEA SPINOSA) } \\ 3202909000 & \text { PROD.CURTIENTES INORGANICOS:PREPARAC. CURTIENTES,INCL CON PROD.CURTIENTES NATURA } \\ 1404103000 & \text { TARA } \\ 1404902000 & \text { TARA EN POLVO (CAESALPINEA SPINOSA) }\end{array}$

Fuente: Sistema Integrado de Información de Comercio Exterior-SIICEX (2019). Adaptación propia

De las partidas indicadas la 1404902000 es de tara en polvo (Caesalpinea Spinosa), que, de acuerdo a los datos de la tabla y figura contigua, en el período 2010-2018, en términos del valor del mercado de las exportaciones-FOB éstos permanecieron casi estables entre los años 2010 y 2016 en alrededor de los 31,5 millones de dólares, pero entre los años 2016 y 2017 se produjo un crecimiento promedio de $4 \%$ y entre el año 2017 y 2018 un crecimiento de $8 \%$. 
Reconociéndose que dicho subproducto representa, del 2000 al 2016 , el $70 \%$ del producto exportado de tara y el $30 \%$ restante corresponden al subproducto mucilago o goma de tara (Ministerio de Agricultura y Riego-MINAGRI, 2017a: 4).

\section{Tabla 6}

Exportaciones de tara en polvo (Miles US\$-FOB)

\begin{tabular}{|r|r|r|r|r|r|r|r|r|r|}
\hline & 2010 & 2011 & 2012 & 2013 & 2014 & 2015 & 2016 & 2017 & 2018 \\
\hline $\begin{array}{c}\text { TARA en } \\
\text { Polvo }\end{array}$ & $27,075.90$ & $29,342.30$ & $31,340.70$ & $31,103.90$ & $32,406.70$ & $31,353.70$ & $32,450.80$ & $35,000.98$ & $39,228.49$ \\
\hline
\end{tabular}

Fuentes: Ministerio de Agricultura y Riego-MINAGRI (2017a: 4-5), Koo (2019). Adaptación propia

Figura 2

Crecimiento de las exportaciones de tara en polvo (Miles US\$-FOB)

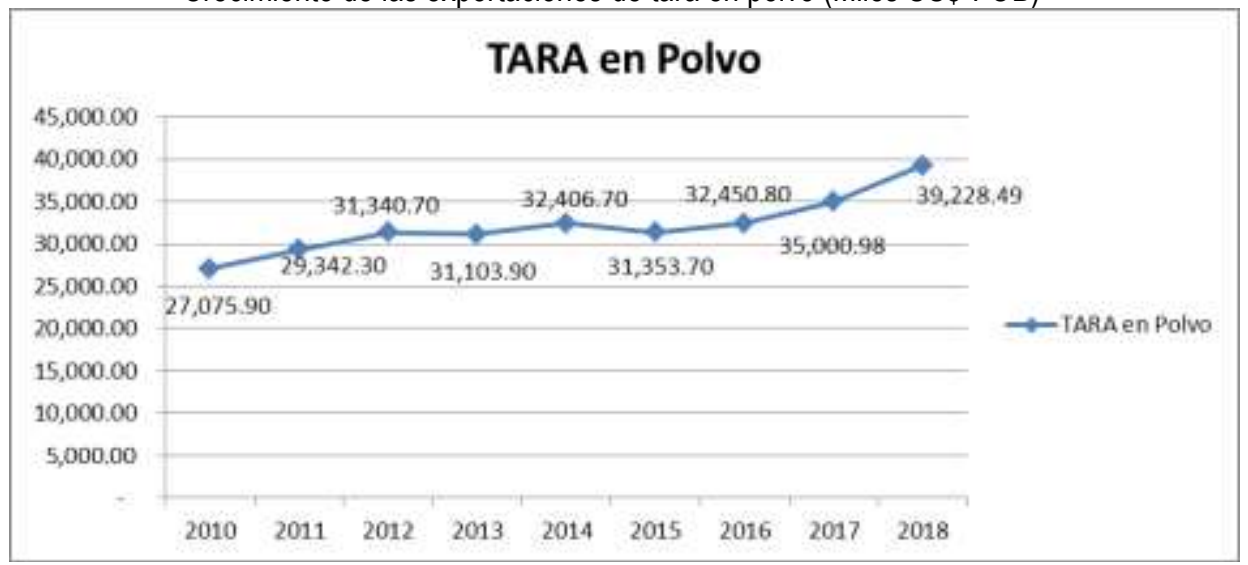

Fuentes: Ministerio de Agricultura y Riego-MINAGRI (2017a, pp. 4-5), Koo (2019). Adaptación propia

\section{Metodología aplicada}

Por la información existente acerca de la unidad de análisis, la tara, datos fragmentados poco organizados y disponibles en instituciones gubernamentales: Ministerio de Agricultura y Riego-MINAGRI (2009, 2010, 2017 a, 2017 b), Ministerio de Agricultura y Riego-MINAGRI y Servicio Nacional Forestal y de Fauna Silvestre-SERFOR (2016, 2017, 2018, 2019), Sistema Integrado de Información de Comercio Exterior- SIICEX (2019), Superintendencia Nacional de Aduanas y de Administración Tributaria-SUNAT (2019) y particulares: Sociedad Nacional de Industrias-SIN (2018).

Así como, por escasos estudios que tratan su competitividad y exportación en el comercio internacional, se definió un nivel de investigación exploratorio.

Aplicándose la técnica de revisión documental y la estadística descriptiva con el resultado de tablas y figuras en función del objetivo planteado. Además, del análisis de la correspondencia del valor FOB de la tara con su producción y precio por kilogramo mediante el instrumento para 
el análisis de la competitividad Costo de los Recursos Domésticos (CRD), que la mide por el factor precio.

También, se analizó la información de la cadena de valor de la tara de acuerdo a la actividad de las tres principales regiones productoras en Perú: Cajamarca (45\%), La Libertad (18\%), Ayacucho (18\%) y la de menor producción: Amazonas (1\%) que corresponde a las de baja producción; incluyendo a las ciudades de Lima, Chiclayo, Trujillo y Huanta que cuentan con empresas procesadoras que realizan la fase de transformación, con la orientación de los 12 pilares del enfoque de competitividad del World Economic Forum-WEF (2018).

\section{Resultados}

Tabla 7

Relación del valor FOB de la tara con su producción y precio por kilo durante el periodo 2010 2018

\begin{tabular}{|r|r|r|r|}
\hline & FOB & PRODUCCIÓN & Precio por Kg \\
\hline 2010 & 27075.9 & 32736 & 0.82709861 \\
\hline 2011 & 29342.3 & 30000 & 0.97807667 \\
\hline 2012 & 31340.7 & 38328 & 0.81769724 \\
\hline 2013 & 31103.9 & 32000 & 0.97199688 \\
\hline 2014 & 32406.7 & 35566 & 0.91117078 \\
\hline 2015 & 31353.7 & 27666 & 1.13329357 \\
\hline 2016 & 32450.8 & 12617 & 2.57199017 \\
\hline 2017 & 35000.98 & 23978 & 1.45971224 \\
\hline 2018 & 39228.49 & 25866 & 1.51660442 \\
\hline
\end{tabular}

Fuente: Superintendencia Nacional de Aduanas y de Administración Tributaria-SUNAT (2019), Koo (2019). Elaboración propia

La tabla 7 muestra respecto al valor FOB de la tara una alza permanente y ascendente desde el año 2010 de 27075.9 FOB a 39228.49 FOB al año 2018 salvo pequeñas disminuciones en el 2013 (31103.9 FOB) y el 2015 (31353.7 FOB), que no tiene correspondencia con la producción, que indica montos descendentes. Por ejemplo, el 2010 la producción fue de 32736 TM., para el 2018 descender a 25866 TM., con alzas significativas el 2012 con 38328 TM., y el 2014 con 35566 TM., además, de una declinación extrema el 2016 con 12617 TM. Situación que explica con más detalle la tabla 7 a partir del comportamiento productivo de la tara por sistema de producción.

Se aplicó, en la tabla 8, el criterio de Chavarría, Sepúlveda y Rojas (2002), mediante uno de los instrumentos para el análisis de la competitividad, el denominado Costo de los Recursos Domésticos (CRD) que la mide por el factor precio, de la siguiente manera:

$\mathrm{CRD}=($ Precio doméstico) $/$ (Precio internacional)

Si: CRD $>1 \rightarrow$ La empresa no es competitiva
CRD $<0 \rightarrow$ La empresa no es competitiva
CRD $<1 \rightarrow$ La empresa es competitiva 


\section{Tabla 8}

Precio Doméstico S/. e Internacional \$ y Competitividad de la tara durante el periodo 2010 2018

\begin{tabular}{|c|c|c|c|c|}
\hline Año & $\begin{array}{c}\text { Precio } \\
\text { Doméstico }\end{array}$ & $\begin{array}{c}\text { Precio } \\
\text { Internacional }\end{array}$ & CRD & Competitividad \\
\hline 2010 & 1.25 & 0.83 & 1.5060241 & No \\
\hline 2011 & 1.83 & 0.98 & 1.86734694 & No \\
\hline 2012 & 1.75 & 0.82 & 2.13414634 & No \\
\hline 2013 & 1.56 & 0.97 & 1.60824742 & No \\
\hline 2014 & 1.42 & 0.91 & 1.56043956 & No \\
\hline 2015 & 1.48 & 1.13 & 1.30973451 & No \\
\hline 2016 & 1.51 & 2.57 & 0.58754864 & Sí \\
\hline 2017 & 1.51 & 1.45 & 1.04137931 & No \\
\hline 2018 & 1.55 & 1.51 & 1.02649007 & No \\
\hline
\end{tabular}

Fuente: Koo (2019), Superintendencia Nacional de Aduanas y de Administración TributariaSUNAT (2019). Adaptación propia

La tabla 8 muestra el precio doméstico en nuevos soles e internacional en dólares americanos del $\mathrm{Kg}$. de la tara, así como, el cálculo del CRD de acuerdo a su fundamento, que indica que el índice es menor que 1 pero mayor a 0 , entonces la empresa es competitiva. De acuerdo a ello se verifico que, en el período 2010-2018, sólo el año 2016 manifestó competitividad debido que el precio internacional por $\mathrm{Kg}$. fue de cerca de $\$ 3.00$ dólares americanos en relación al precio doméstico de S/. 1.51 nuevos soles y, ello a pesar que Perú tiene la mayor producción de tara a nivel mundial $(90 \%)$ y es el segundo exportador mundial.

\section{Tabla 9}

Comportamiento productivo de la tara por sistema de producción: Bosques naturales, plantaciones forestales y plantas en macizo.

\begin{tabular}{|c|c|c|c|c|c|}
\hline Regiones & $\begin{array}{l}\text { Bosques } \\
\text { naturales }\end{array}$ & $\begin{array}{l}\text { Plantaciones } \\
\text { forestales }\end{array}$ & $\begin{array}{l}\text { Plantas en } \\
\text { macizo }\end{array}$ & Explotación & Rendimiento \\
\hline $\begin{array}{l}\text { Cajamarca } \\
\text { (Produjo 6, } \\
297 \text { TM. el } \\
2015 \text { ) }\end{array}$ & $\begin{array}{l}\text { Hay } 66 \% \text { de } \\
\text { plantas }\end{array}$ & $\begin{array}{l}\text { Hay } 34 \% \text { de } \\
\text { plantas. } \\
\text { Aumentando } \\
26 \% \text { más } \\
\text { por } \\
\text { plantaciones } \\
\text { nuevas }\end{array}$ & $\begin{array}{l}\text { Hay } 74 \% \\
\text { por } \\
\text { plantaciones } \\
\text { nuevas. }\end{array}$ & $\begin{array}{l}\text { Bajo riego rinde } \\
\text { entre } 25 \text { a } 46 \mathrm{Kg} \text {. } \\
x \quad \text { árbol } \\
\text { (Plantaciones } \\
\text { forestales y } \\
\text { plantas } \\
\text { macizo) } \\
\text { Se produce de } \\
1,500 \mathrm{Ha} \text {. a más. } \\
\text { En } 98 \% \text { de } \\
\text { bosques } \\
\text { naturales y } 2 \% \text { de } \\
\text { plantaciones } \\
\text { Alcanzando } \\
\text { 1,335 kg. } x \mathrm{Ha} \text {. }\end{array}$ & $\begin{array}{l}91 \% 20 \mathrm{Kg} . \mathrm{x} \\
\text { árbol } \\
9 \% \quad 10 \mathrm{~kg} . \mathrm{x} \\
\text { árbol. } \\
\text { Rinde } \\
\text { limitadamente } \\
\text { en bosques } \\
\text { naturales que } \\
\text { produce en } \\
\text { secano (no } \\
\text { hay sistema } \\
\text { de riego). }\end{array}$ \\
\hline
\end{tabular}




\begin{tabular}{|c|c|c|c|c|c|}
\hline $\begin{array}{l}\text { Ayacucho } \\
\text { (Produjo 11, } \\
247 \text { TM. el } \\
2015 \text { ) }\end{array}$ & $\begin{array}{l}\text { Hay } 65 \% \text { de } \\
\text { plantas en } \\
520 \mathrm{Ha} \text {. }\end{array}$ & $\begin{array}{l}\text { Hay } 35 \% \text { de } \\
\text { plantas en } \\
290 \mathrm{Ha} .\end{array}$ & NO HAY & $\begin{array}{lr}810 & \mathrm{Ha} \\
\text { cultivadas } & \\
324,000 \text { árboles } \\
\begin{array}{l}\text { de tara. } \\
4,000\end{array} \\
\begin{array}{l}\text { potenciales } \\
\text { nuevas }\end{array} \\
\text { plantaciones }\end{array}$ & $\begin{array}{l}24 \quad \mathrm{~kg} . \quad \text { en } \\
\text { vaina de tara x } \\
\text { árbol } \\
\text { (heterogéneo } \\
\text { el rendimiento } \\
\text { x provincias) }\end{array}$ \\
\hline $\begin{array}{l}\text { La Libertad } \\
\text { (Produjo 3, } \\
668 \text { TM. el } \\
2015 \text { ) }\end{array}$ & $\begin{array}{l}\text { Mayormente } \\
\text { en } 80 \text { a } 90 \%\end{array}$ & $\begin{array}{l}\text { Hay } 10 \% \text { de } \\
\text { plantas }\end{array}$ & $\begin{array}{l}\text { Sectores } \\
\text { cultivados } \\
\text { que rinden } \\
\text { de } 14,375 \text { a } \\
10,000 \mathrm{Kg} . \mathrm{x} \\
\mathrm{Ha} .\end{array}$ & & $\begin{array}{l}25 \text { a } 70 \mathrm{Kg} . \text { por } \\
\text { planta } \\
\text { dependiendo } \\
\text { del manejo de } \\
\text { agua. }\end{array}$ \\
\hline $\begin{array}{l}\text { Amazonas } \\
\text { (Produjo } \\
726 \text { TM. el } \\
2015 \text { ) }\end{array}$ & & & & $\begin{array}{l}\text { La producción de } \\
\text { tara en la Región } \\
\text { ha oscilado las } \\
150 \mathrm{TM} \text {, lo que } \\
\text { representa el } 1 \% \\
\text { de la producción } \\
\text { nacional. }\end{array}$ & $\begin{array}{l}\text { Rendimiento } \\
\text { es entre } 10 \text { y } \\
14 \text { kilos por } \\
\text { árbol, lo que } \\
\text { equivale a } \\
\text { unos 2,400 } \\
\text { kilos por } \\
\text { hectárea. }\end{array}$ \\
\hline
\end{tabular}

Fuentes: Chávez (2013, pp. 19, 20, 21), Avendaño (2008, pp. 24, 25 y 26), Universidad Nacional Agraria La Molina-UNALM (2015), Ministerio de Comercio Exterior y Turismo-MINCETUR (2007, p 5), Ministerio de Agricultura y Riego-MINAGRI (2017a, p 24). Adaptación propia.

La tabla 9 indica el comportamiento productivo de la tara por sistema de producción: Bosques naturales, plantaciones forestales y plantas en macizo, notándose con claridad los limitantes en su productividad por ser preponderante el de bosques naturales que produce el 80\% de la producción nacional León (2018 b), que según (Ministerio de Agricultura y RiegoMINAGRI y Servicio Nacional Forestal y de Fauna Silvestre-SERFOR, 2017), producen entre 10-20 Kg./planta en condiciones poco favorables por ser en secano (supeditado a lluvias y/o con limitado sistema de riego) 0, por estar agrupadas en pequeñas áreas 0 aisladas en algunos casos llegando a producir mayormente $10 \mathrm{Kg}$./planta, siendo lo que más abunda. Que es diferente en 7,000 hectáreas donde proyectos del Estado y empresas privadas sembraron plantas forestales incluyendo las de macizo que producen entre $20-40 \mathrm{Kg}$. /planta por condiciones favorables de sistema de riego y silvicultura abarcando sólo el $20 \%$ de la producción.

Además, hay que tener en cuenta los siguientes factores: Condiciones climáticas (Temperatura y precipitaciones), silvicultura, producción bajo riego (Produce a partir de 4 años), producción en secanos (Produce entre 7 a 8 años), interdependencia entre interacción genética y producción de taninos y medio ambiente, el piso ecológico, que de acuerdo a la tabla indicada no es favorable. 


\section{Conclusiones}

Los resultados permiten enunciar que la tara peruana no fue competitiva en el comercio internacional durante el período 2010-2018, sólo el año 2016 manifestó competitividad debido que el precio internacional por $\mathrm{Kg}$. fue de cerca de $\$ 3.00$ dólares americanos en relación al precio doméstico de S/. 1.51 nuevos soles, quedando 8 años de baja competitividad.

El sistema de producción preponderante que se realiza en bosques naturales en condiciones poco favorables es una de sus causales, además, de las deficiencias que existen en todas las actividades de la cadena de valor de la tara medidas con los 12 pilares impulsores de la productividad.

Por lo que es necesario mejorar la actividad en cada fase agregando valor en ellas y superando las restricciones comerciales, organizacionales, tecnológicas para que la competitividad suba de nivel, estando acorde con las demandas que el proceso de globalización impone referente a desarrollar innovaciones para la generación de los productos con nuevos procesos que permitan cambios organizacionales y estrategias de mercado, como refieren Palacios y Cotes (2016), que permitiría al país andino transitar en mejores condiciones de la estructura de exportación basada en ventajas comparativas a su transformación sustentada en ventajas competitivas.

\section{Referencias Bibliográficas}

Avendaño, Efraín (2008) Conociendo la cadena productiva de tara en Ayacucho. SOLID PERÚ. Extraído de: https://es.slideshare.net/lilianaarcegomez/conociendolacadenaproductivadetaraenayacuchomayo20081 consulta: 05/03/2019.

Cann, Oliver (2016) ¿Qué es la competitividad? World Economic Forum. Extraído de: https://es.weforum.org/agenda/2016/10/que-es-la-competitividad consulta 17/11/2018.

Chavarría Hugo, Sepúlveda Sergio y Rojas Patricia (2002). Competitividad: Cadenas agroalimentarias y territorios rurales: Elemento conceptuales. Editor IICA Biblioteca Venezuela. Extraído de: https://www.worldcat.org/title/competitividad-cadenasagroalimentarias-y-territorios-rurales-elelmento-conceptuales/oclc/804175170/viewport consulta: 16/11/2019.

Chávez, Manuel (2013). La cadena de valor de la tara en la región Cajamarca. Análisis y lineamientos estratégicos para su desarrollo. Proyecto Perúbiodiverso - PBD, Cooperación Suiza - SECO, Deutsche Gesellschaft für Internationale Zusammenarbeit (GIZ) $\mathrm{GmbH}^{*}$ - Programa Desarrollo Rural Sostenible (PDRS), Ministerio de Comercio Exterior y Turismo - Mincetur, Comisión de Promoción del Perú para la Exportación y el Turismo - Promperú, Ministerio del Ambiente - Minam. Extraído de: https://pt.scribd.com/doc/158473365/Cadena-Valor-Tara consulta: 6/02/2019.

Consejo Nacional de Competitividad y Formalización (2019). Política nacional de competitividad y productividad. Ministerio de Economía y Finanzas - Consejo Nacional de $\begin{array}{llll}\text { Competitividad } y & \text { Formalización. }\end{array}$ de:https://cdn.www.gob.pe/uploads/document/file/300526/d288579_opt.pdf consulta $17 / 11 / 2018$.

Cordero, Martha (2005) Comunidad Andina: un estudio de su competitividad exportadora. Naciones Unidas CEPAL. Extraído de: 
https://repositorio.cepal.org/bitstream/handle/11362/4946/S05132_es.pdf?sequence=1\& isAllowed=y consulta: 16/11/2019.

Daniels, John, Radebaugh, Lee y Sullivan, Daniel (2013) Negocios Internacionales Ambientes

y operaciones. (Decimosegunda edición) México: Pearson Educación. Extraído de: https://es.scribd.com/document/273912435/Negocios-Internacionales-Ambientes-yOperaciones consulta: 16/11/2019.

García, Alan y Fernández, Rosario (2011). Ley Forestal y de Fauna Silvestre No $29763 \mathrm{El}$

Peruano, pp. 446980-447004. Extraído de:

http://www.peru.gob.pe/docs/PLANES/14282/PLAN_14282_2015_Ley_29763_Ley\%20

Forestal\%20y\%20de\%20Fauna\%20Silvestre.pdf consulta: 16/11/2019.

Gómez, Daniel (2017) La innovación como factor de competitividad en Latinoamérica. Foro

Económico Mundial. Extraído de https://es.weforum.org/agenda/2017/03/la-innovacioncomo-factor-de-competitividad-en-latinoamerical consulta: 16/11/2018.

Koo, Wilfredo (2018). Arándanos Perú Exportación 2018 noviembre [mensaje en un blog] AGRODATAPERÚ.

Extraído

de:

https://www.agrodataperu.com/category/exportaciones/arandanos-2 consulta: 16/01/2019.

Koo, Wilfredo (2019) Tara en Polvo Perú Exportación 2018 diciembre. [Mensaje en un blog] AGRODATAPERÚ. Extraído de: https://www.agrodataperu.com/2019/01/tara-en-polvoperu-exportacion-2018-diciembre.html consulta: 31/10/2019.

Lam, Rosa (2016) La redacción de un artículo científico. Rev. Cubana Hematol Inmunol Hemoter vol.32 no.1 Ciudad de la Habana ene.-mar. Extraído de: http://scielo.sld.cu/scielo.php?script=sci_arttext\&pid=S0864-02892016000100006 consulta: 11/03/2019.

León, José (2018a) Agraria.pe. Lima-Perú.: Agencia Agraria de Noticias Extraído de: http://agraria.pe/noticias/peru-produce-mas-del-90-de-la-tara-a-nivel-mundial-16304 consulta: 16/02/2019.

León, José (2018b). Perú produce más del $90 \%$ de la tara a nivel mundial. Agraria.pe. Extraído de: http://agraria.pe/noticias/peru-produce-mas-del-90-de-la-tara-a-nivel-mundial-16304 consulta: 16/02/2019.

Lerma, Alejandro y Márquez, Enrique (2010) Comercio y Marketing Internacional (cuarta edición).

http://www.elmayorportaldegerencia.com/Libros/Mercadeo/[PD]\%20Libros\%20\%20Comercio\%20y\%20Marketing\%20internacional.pdf consulta: 27/02/2019.

Llacchuas, David (2016) Análisis de las limitantes en la competitividad de la cadena productiva de la tara (Caesalpinia spinosa) en la Región de Apurímac. Tesis para optar el título profesional de Ingeniero Agroindustrial Universidad Nacional José María Arguedas. Extraído de: http://repositorio.unaima.edu.pe/bitstream/handle/123456789/216/22-2016EPIA-Llacchuas\%20Valdivia-

AN\%C3\%81LISIS\%20DE\%20LAS\%20LIMITANTES\%20EN\%20LA\%20COMPETITIVID AD\%20DE\%20LA\%20CADENA\%2OPRODUCTIVA\%20DE\%20LA\%20TARA \%20\%202 016.pdf?sequence $=1$ \&isAllowed=y consulta 15/11/2018.

Ministerio de Agricultura y Riego-MINAGRI (2009) Perú produce el $80 \%$ de la tara a nivel mundial. Ministerio de Agricultura fomenta producción de tara a gran escala para 
exportación. Extraído de http://www.minagri.gob.pe/portal/notas-de-prensa/2009/2900peru-produce-el-80-de-la-tara-a-nivel-mundial consulta: 15/06/2017.

Ministerio de Agricultura y Riego-MINAGRI (2010) Resolución Suprema 013-2010-AG. Marco

legal. Extraído de: http://www.minagri.gob.pe/portal/resoluciones-supremas/rs2010/4473-resolucion-suprema-013-2010-ag consulta: 14/02/2019.

Ministerio de Agricultura y Riego-MINAGRI (2017a) ABC de la producción y comercio de la tara en el Perú.

Extraído de:

https://webcache.googleusercontent.com/search?q=cache:ZTsp69F8-

cYJ:https://www.minagri.gob.pe/portal/analisis-economico/analisis-

2017\%3Fdownload\%3D10796:la-produccion-y-comercio-de-tara-en-elperu+\&cd=25\&hl=es\&ct=clnk\&gl=pe consulta: 16/11/2019.

Ministerio de Agricultura y Riego-MINAGRI (2017b) Las exportaciones agrarias aumentaron 8\%, en enero-mayo 2017. Comercio Exterior Agrario. Extraído de:http://siea.minagri.gob.pe/siea/sites/default/files//nforme\%20de\%20Comercio\%20Ext erior\%20Enero-May0\%202017_2.pdf consulta: 21/11/2018.

Ministerio de Agricultura y Riego-MINAGRI (2019) Boletín Estadístico Mensual-diciembre 2018: "El Agro en Cifras". Sistema de Información Estadística Agraria - SIEA. El Perú Primero. Extraído de: http://siea.minagri.gob.pe/siea/sites/default/files/boletin-estadisticomensual-el-agro-en-cifras-dic18 250319 0.pdf consulta 16/11/2019.

Ministerio de Agricultura y Riego-MINAGRI y Servicio nacional Forestal y de Fauna SilvestreSERFOR (2016) "Perú Forestal en Números 2015". Extraído de: http://repositorio.serfor.gob.pe/handle/SERFOR/418 consulta: 12/02/2019.

Ministerio de Agricultura y Riego-MINAGRI y Servicio Nacional Forestal y de Fauna SilvestreSERFOR (2017) El aprovechamiento de la especie tara o taya en el marco de la legislación forestal vigente. Extraído de: https://www.serfor.gob.pe/wpcontent/uploads/2017/02/Impacto\%20en $\% 20$ el\%20aprovechamiento $\% 20 \mathrm{de} \% 20 \mathrm{la} \% 20 \mathrm{t}$ ara.pdf consulta: 13/02/2019.

Ministerio de Agricultura y Riego-MINAGRI y Servicio nacional Forestal y de Fauna SilvestreSERFOR (2018) Anuario Forestal y de Fauna Silvestre 2016. Extraído de: https://www.serfor.gob.pe/wp-content/uploads/2018/10/Anuario-2016.pdf $\quad$ consulta: 12/02/2019.

Ministerio de Agricultura y Riego-MINAGRI y Servicio nacional forestal y de fauna silvestreSERFOR (2019) Anuario Forestal y de Fauna Silvestre 2017. Extraido de: https://www.serfor.gob.pe/wp-content/uploads/2019/02/Anuario-Forestal-y-de-FaunaSilvestre-2017.pdf consulta: 12/02/2019.

Ministerio de Comercio Exterior y Turismo-MINCETUR (2007) Plan Operativo de la Tara Región Amazonas. Extraido de: https://www.mincetur.gob.pe, Perx_Amazonas , POP_TARA_AMAZONAS consulta: 16/11/2019.

Ojeda, José, Méndez, Sergio y Hernández, Roberto (2016) El liderazgo y su relación con el Modelo de Valores en Competencia. Revista TELOS. Vol. 18, No. 1 Venezuela (Pp. 1738). Extraído de: https://es.calameo.com/read/00557333879d36c9fcd94 consulta: 16/11/2019.

Palacios, Lilia y Cotes, Gilberto (20016) Innovación tecnológica. Caso: Centro de Audiovisuales de la Universidad de la Guajira colombiana. Revista TELOS. Vol. 18, №3 Venezuela (Pp. 
362 - 380). Extraído de: https://es.calameo.com/books/00557333854903fd804ce consulta: 31/10/2019.

Paz, Juliana (2017) Transferencia del Conocimiento como Agente Articulado de la Competitividad en el Sector Bancario. Revista TELOS Vol. 19, No. 3, Venezuela. (Pp. 408-430), Extraído de: http://ojs.urbe.edu/index.php/telos/article/view/724/654 consulta: $16 / 11 / 2019$.

Porter, Michael (2008) Ventaja Competitiva creación y sostenimiento de un desempeño superior. Continental S.A. México.

Ricardo, David (2003). Principios de Economía Política y Tributación. Editorial Pirámide. España.

Rosales, Selene (2019). Exportadores peruanos de Paltas Hass se alistan para llegar a cinco nuevos mercados. Asociación de Productores de Palta Hass del Perú (Prohass) adelanta que envíos llegarían a Corea del Sur en el 2019. Diario GESTIÓN, Economía. pp. 15-17 Extraído de: https://gestion.pe/economia/paltas-hass-peruana-alista-llegar-cinconuevos-mercados-256608. consulta: 27/01/2019.

Sistema Integrado de Información de Comercio Exterior-SIICEX a (2019). Producto Tara. Extraído

de: http://www.siicex.gob.pe/siicex/portal5ES.asp?_page $=172.17100 \&$ portletid_=sfichapr oductoinit\&scriptdo=cc fp init\&pproducto $=\% 20192 \% 20 \&$ pnomproducto $=\% 20$ Tara consulta: 31/10/2019.

Sociedad Nacional de Industrias-SNI (2018) Wef publica informe de competitividad global 2018 con nueva estructura. Centro de Desarrollo Industrial. Extraído de: http://www.cdi.org.pe/pdf/IGC/2018/Nota_de_prensa_PERU.pdf consulta: 31/10/2019.

Superintendencia Nacional de Aduanas y de Administración Tributaria SUNAT (2019) Boletín Anual. Extraído de:

http://www.sunat.gob.pe/cuentassunat/planestrategico/memoralnstitucional.html consulta: 12/03/2019.

Telge, Herbert (2018). Entre enero y agosto del 2018 exportación de tara creció 19\%. Perú Exporta Asociación de Exportadores. Extraído de: http://www.adexperu.org.pe/wpcontent/uploads/2018/11/boletin_semanal_peru_exporta_n278.pdf consulta: 04/02/2019.

Universidad Nacional Agraria La Molina-UNALM (2015) Lineamientos para la el manejo de plantaciones de tara (caesalpineaspinosa) para la rehabilitación de tierras eriazas del trópico sub-humedo de la región de la costa del Perú. Extraído de: http://webcache.googleusercontent.com/search?q=cache:CclaZIN2bFkJ:www.itto.intfile s/itto_project_db_input/3097/Technical/PD724-13-TechRepOutput1-2-

ELABORACION\%2520DE\%2520LA\%2520LINEA\%2520DE\%2520BASE\%2520Y\%252 OESTABLECIMIENTO\%2520DE\%2520UN\%2520PROGRAMA\%2520DE\%2520PARCE LAS.pdf+\&cd=20\&hl=es\&ct=clnk\&gl=pe consulta: 31/10/2019.

World Economic Forum - WEF (2018). The Global Competitiveness Report 2018. Extraído de: http://www3.weforum.org/docs/GCR2018/05FullReport/TheGlobalCompetitivenessRepo rt2018.pdf consulta: 31/10/2019. 